\title{
Referências de cidadania e democracia nos relatórios finais das Conferências Nacionais de Saúde.
}

\section{References to citizenship and democracy in the final reports of the National Health Conferences.}

\section{Las referencias a la ciudadanía y la democracia en los informes finales de las Conferencias Nacionales de Salud.}

Ivan PRICKEN DE BEM

Ione Silva BARROS

Adriana Modesto de SOUSA

Pollyana Rodrigues Pinheiro DIAS ${ }^{4}$

RESUMO: Este estudo apresenta reflexões acerca dos conceitos de cidadania e democracia no contexto das Conferências Nacionais de Saúde - CNS tendo como fonte de referência seus relatórios finais e a série histórica $8^{\mathrm{a}} \mathrm{CNS}$ a $14^{\mathrm{a}} \mathrm{CNS}$. As variáveis elencadas foram a cidadania e a democracia, buscando-se perscrutar referências explícitas e/ou implícitas aos referidos termos. Por meio de análise documental buscou-se identificar em que momentos, que atores sociais ou ramo da saúde estes termos foram de forma mais recorrente referidos. Percebe-se a contribuição histórica das CNS, sendo o SUS seu grande legado, assim como a extrema relevância nas discussões deflagradas em seus contextos imputada aos termos cidadania e democracia sendo o controle social/ participação social o espaço mais profícuo a estas discussões.

Palavras-chave:Conferências de Saúde, Democracia, Participação Social

\footnotetext{
ABSTRACT: Thisstudy presentsreflections on theconcepts of citizenship anddemocracyin the contextof theNational Health Conferences-CNStakingas a reference sourcetheir final reportsandCNS8thtime seriesthe 14thCNS. The variableslistedwerecitizenshipanddemocracy, trying to peer intoexplicit and/ orimplicitreferencesto theseterms. Throughdocument analysissought

1 Pesquisador Colaborador - Fundação Osvaldo Cruz - FIOCRUZ/DIREB - Programa Direito Sanitário PRODISA e especialista em Direito Sanitário - ivanprk@gmail.com;

2 Mestranda em Saúde Coletiva da Faculdade de Ciências da Saúde - FS/UnB, Pesquisadora do Núcleo de Estudos em Saúde Pública - NESP/UnB e Especialista em Direito Sanitário - ionesilvabarros81@gmail.com; 3 Mestre em Ciências da Saúde - UnB, Especialista em Gestão de Saúde - UnB e Docência Superior, Graduada em Letras e Saúde Coletiva - UnB - anairdamodesto@gmail.com;

4 Especialista em Direito Sanitário - pollyanarpdias@gmail.com.
} 
to identifyat what times, which socialactors orthe health fieldthese termswerementionedmost recurrentform. Realizes thehistorical contributionof theCNS, with theSUShis greatest legacy, as well as extremely relevantin discussionsordnancein their contextsimputedto the termscitizenship, democracyandsocial control/social participationthe mostprolificspacefor thesediscussions.

Keywords:Health Conferences, Democracy, Social Participation

RESUMEN: Este estudio presenta reflexiones sobre los conceptos de ciudadanía y la democracia en el contexto de las Conferencias Nacionales de Salud - CNS tomando como fuente de referencia de sus informes finales y SNC octava serie de tiempo del 14 SNC. Las variables listadas eran la ciudadanía y la democracia, tratando de escudriñar en referencias explícitas y / o implícitas a estos términos. A través del análisis de documentos tratado de identificar en qué momento, que los actores sociales o el campo de la salud estos términos se mencionan forma más recurrente. Da cuenta de la contribución histórica del sistema nervioso central, con el SUS su mayor legado, así como de gran relevancia en las discusiones de las municiones en sus contextos imputada a los términos de ciudadanía, la democracia y el control social / participación social el espacio más prolífico para estas discusiones.

Palabras clave: Conferencias de Salud, Democracia, Participación Social

\section{INTRODUÇÃO}

O termo cidadania remete ao vocábulo cidadão cuja semântica é: aquele que habita uma cidade ou "indivíduo no gozo dos direitos civis e políticos de um Estado". Salienta-se que a Constituição Federal de $1988^{2}$ 'é referida pelo senso comum como a constituição cidadã, dentre outros motivos por reconhecer e ampliar os direitos civis e sociais da população, entre estes a saúde, sendo dever do Estado provê-la. Destaca-se que a discussão acerca do direito à saúde remete às CNS que precederam a promulgação do texto constitucional, dentre estas a $8^{\text {a }}$ CNS ocorrida em 1986. Embora o mote principal desta CNS (e das demais) seja a saúde, em função do período ditatorial experimentado pelo Brasil à época, teve em seu bojo outras discussões, outros pleitos que passam pelo resgate à cidadania e à democracia. Era, portanto, a materialidade da resistência e da luta contra o modelo político da época, contando com o protagonismo de vários sujeitos: profissionais de saúde, sociedade civil, gestores.

A palavra democracia tem sua origem nos vocábulos gregos děmocratǐa ${ }^{3}$, demokrátia ${ }^{1}$ cujo significado é "governo do povo; Sistema político baseado na participação do povo". Tendo em vista a semântica pertinente a cidadania e democracia pode-se entender que têm em sua essência no que tange à saúde o estabelecimento da interação: atores sociais/Estado. A forma como se estabelece esta interação poderá dimensionar também qual seja a relevância e o papel atribuído à cidadania e democracia, no caso deste estudo, nos contextos das CNS. Salienta-se que as Conferências de Saúde revelam tendências, anseios e demandas sociais emergentes/recorrentes. Pode-se definir as Conferências de Saúde como4: 
[...] espaços institucionais destinados a analisar os avanços e retrocessos do SUS e propor diretrizes para a formulação de políticas de saúde em níveis correspondentes. São vitais para o exercício do controle social, pois estabelecem diretrizes para a atuação dos conselhos de Saúde nas três esferas de governo. [...] As conferências nacionais de saúde devem ocorrer a cada quatro anos, com a representação dos vários segmentos sociais, para avaliar a situação de saúde e propor as diretrizes para a formulação da política de Saúde nos níveis de correspondentes, convocada pelo Poder Executivo ou, extraordinariamente, por esta ou pelo Conselho de Saúde.

As Conferências e conselhos de saúde constituem o espaço estabelecido no marco legal para a participação social. Embora sua existência remonte aos anos 30 do século vinte, é somente a partir da Constituição Federal de 1988 que assumem o caráter de espaço público que hoje apresentam. No período anterior, as conferências eram espaços de articulação intergovernamental, com participação restrita a gestores, técnicos e especialistas convidados pelos ministros de Estado 5 .

Neste Sentido, o objetivo principal deste estudo foi de perscrutar referências explícitas e/ou implícitas dos termos cidadania e democracia nos relatórios finais da $8^{\mathrm{a}}$ à $14^{\mathrm{a}}$ Conferência Nacional de Saúde - CNS e identificar que atores sociais ou ramo da saúde estes termos foram de forma mais recorrentemente referidos.

\section{METODOLOGIA}

Este estudo é de natureza exploratória ${ }^{6}$ a partir de análise documental ${ }^{7}$, tendo como fonte de referência os relatórios finais das CNS tendo em vista a série histórica 8 a CNS a $14^{\text {a }} \mathrm{CNS}$ disponíveis na web na forma eletrônica.

\section{RESULTADOS}

A partir da análise dos relatórios finais das CNS tendo em vista a série histórica $8^{\mathrm{a}} \mathrm{CNS}$ a $14^{\mathrm{a}}$ CNS, percebe-se que a variável democracia não aparece nas $8^{\mathrm{a}}, 9^{\mathrm{a}}$ e $10^{\mathrm{a}}$ conforme destacado no quadro 01.

Quadro 1- Descrição da Variável Democracia nos Relatórios Finais das CNS ( $8^{\mathrm{a}}$ a $\left.14^{\mathrm{a}}\right)$

\begin{tabular}{|c|c|l|}
\hline Conferência & $\mathbf{N}^{\mathbf{0}}$ de menções & \multicolumn{1}{|c|}{ Eixos temáticos em que foram abordados } \\
\hline $8^{\mathrm{a}}$ & - & \\
\hline $9^{\mathrm{a}}$ & - & \\
\hline $10^{\mathrm{a}}$ & - & \\
\hline $11^{\mathrm{a}}$ & 1 & Gestão e Organização do SUS \\
\hline $12^{\mathrm{a}}$ & 5 & $\begin{array}{l}\text { Vigilância, Políticas Públicas, Comunicação em Saúde, Política, Movimentos } \\
\text { Sociais }\end{array}$ \\
\hline $13^{\mathrm{a}}$ & 4 & $\begin{array}{l}\text { Formação em Saúde, Resgate dos temas da } 8^{\mathrm{a}} \text { Conferência, Política de Paz, } \\
\text { Fomento a Democracia }\end{array}$ \\
\hline $14^{\mathrm{a}}$ & 1 & Consolidação dos Pleitos por meio da democracia \\
\hline
\end{tabular}

Fonte: Relatórios finais das Conferências Nacionais de Saúde $8^{\mathrm{a}}$ à $14^{\mathrm{a}}$. 
Nas conferências que se seguem $11^{\mathrm{a}} 12^{\mathrm{a}} 13^{\mathrm{a}}$ e $14^{\mathrm{a}}$, a variável democracia são abordadas onze vezes sendo retratadas nos discursos dos gestores e profissionais de saúde nos eixos temáticos fazem inferência ao fortalecimento dos princípios organizativos do SUS e criação de atividades e espaços que estimulem a democracia e participação social.

Relacionados à cidadania, tal variável também se mostrou ausente, pelo menos em sua forma explícita nas $8^{\mathrm{a}}, 9^{\mathrm{a}}$ e $10^{\mathrm{a}}$ Conferências Nacionais de Saúde, como mostra o quadro 2

Quadro 2- Descrição da Variável Cidadania nos Relatórios Finais das CNS ( $8^{\mathrm{a}}$ a $14^{\mathrm{a}}$ )

\begin{tabular}{|c|c|c|}
\hline Conferência & $N^{0}$ de menções & Eixos temáticos em que foram abordados \\
\hline $8^{\mathrm{a}}$ & - & - \\
\hline $9^{a}$ & - & - \\
\hline $10^{\mathrm{a}}$ & - & - \\
\hline $11^{\mathrm{a}}$ & 13 & $\begin{array}{l}\text { Controle Social, Efetivação do SUS, Comunicação em Saúde, Articulação } \\
\text { Ministério Publico Estadual e Promotorias de Saúde, Capacitação, Modelos } \\
\text { de Atenção, Combate a Mercantilização da Saúde, Reorientação do Modelo } \\
\text { Assistencial, Reabilitação, Politicas de Informação, Educação e Comunicação }\end{array}$ \\
\hline $12^{\mathrm{a}}$ & 25 & $\begin{array}{l}\text { Saúde do Trabalhador, Princípios do SUS e Constituição, Direitos de } \\
\text { Cidadania, Condições de Vida e Participação Social, Relações Estado } \\
\text { e Sociedade, Acesso a Informação, Pessoa com Deficiência, Estado } \\
\text { Democrático, Ações de Cidadania, Políticas Públicas, Construção da } \\
\text { Cidadania e Inclusão Social, Governo e Sociedade, Intersetorialidade, } \\
\text { Transformação de Espaços Públicos, Saúde de Grupos Populacionais } \\
\text { Específicos, Saúde na Escola, Controle Social, Educação Popular em Saúde, } \\
\text { Humanização, Modelos de Atenção a Saúde }\end{array}$ \\
\hline $13^{\mathrm{a}}$ & 20 & $\begin{array}{l}\text { Direito Humano a Saúde, Políticas Intersetoriais, Emprego e Renda, Lei } \\
\text { Orgânica de Assistência Social, Intersetorialidade, Políticas Públicas de } \\
\text { Saúde, Educação Permanente, Política Nacional de Saúde Integral, Saúde } \\
\text { Bucal, Pacto pela Saúde, Desenvolvimento Social, Educação e Saúde, } \\
\text { Participação Social, Movimentos Sociais, Desigualdades Sociais, Condições } \\
\text { de Vida, Controle Social }\end{array}$ \\
\hline $14^{\mathrm{a}}$ & 8 & $\begin{array}{l}\text { Comunicação em Saúde, Educação e Saúde, Políticas Públicas para grupos } \\
\text { Específicos, População Negra, Trabalho Rural, Internação Compulsória }\end{array}$ \\
\hline
\end{tabular}

Percebe-se que esta variável foi mais recorrente do que a que retratou sobre democracia. “Cidadania" foi mencionada 13 vezes na $11^{\mathrm{a}} \mathrm{CNS}, 25$ vezes na $12^{\mathrm{a}}, 20$ vezes na $13^{\mathrm{a}}$ e 8 vezes na $14^{\mathrm{a}}$. Infere-se, portanto, que apesar das varáveis democracia e cidadania estarem intimamente imbricadas, nestas Conferências a variável cidadania parecia estar mais clara no entendimento dos participantes conforme é possível verificar no quadro deste estudo.

Não ficaram explícitos quais atores elaboraram as propostas dos eixos temáticos elencados para este trabalho, pois, diversos segmentos da sociedade (deputados, profissionais da saúde, usuários 
etc.) contribuíam para o fortalecimento dos referidos assuntos.

Dos temas encontrados nos eixos temáticos, os mais recorrentes nas Conferências foram o controle social, comunicação em saúde, modelos de atenção, participação social, políticas públicas, educação e saúde e intersetorialidade. Outros como políticas para grupos específicos aparecem apenas nas últimas Conferências. Tal constatação deixa claro que ainda existem lacunas a serem corrigidas /preenchidas em relação a estes temas, principalmente em relação ao controle social, políticas públicas, participação popular e educação em saúde, temas que se apresentam em pelo menos três Conferências consecutivas.

\section{DISCUSSÃO}

Mesmo sendo a $8^{\text {a }}$ CNS palco do maior processo democrático da história da saúde no Brasil, grande matriz da Reforma Sanitária, foram observados poucos avanços no campo mesmo sendo esse o movimento sustentado por diversos pilares da democracia e cidadania.

Jairnilson Paim vai de encontro a essa afirmativa ao classificar a reforma Sanitária brasileira, como uma reforma social centrada em diversos elementos como ${ }^{8}$ :

Democratização da saúde, implica a elevação da consciência sanitária sobre saúde e seus determinantes e o reconhecimento do direito à saúde, inerente à cidadania; Democratização do Estado e seus aparelhos, respeitando o pacto federativo, assegurando a descentralização do processo decisório e o controle social". Democratização da Sociedade alcançando os espaços de organização econômica e da cultura.

A $8^{\text {a }}$ CNS, em 1986 foi um marco histórico na saúde no Brasil, pois contou com a participação da população nas discussões, ao contrário do que se via em conferenciais anteriores, passando de um caráter estritamente técnico para incorporar outros setores da sociedade.

Neste período o Brasil estava passando por um contexto de transição de militarização (década de 1970) para início dos tempos democráticos, ou seja, regime pelo qual os governantes são eleitos pelo povo. Os anos 80 , cenário onde ocorreu a 8 a CNS, a partir do governo Sarney, foram garantidos o clima de liberdade democrática, sendo esse um dos pontos positivos deste governo. Destacase, no entanto que o período foi marcado por um panorama de desconforto financeiro, inflação e congelamentos de preços nesse período.

Sarlet (1988) define a dignidade da pessoa humana como9:

[...] a qualidade intrínseca e distintiva de cada ser humano que o faz merecedor do mesmo respeito e consideração por parte do Estado e da comunidade, implicando, neste sentido, um complexo de direitos e deveres fundamentais que assegurem a pessoa tanto contra todo e qualquer ato de cunho degradante e desumano, como venham a lhe garantir as condições existenciais 
mínimas para uma vida saudável.

Neste sentido, a efetividade do direito à saúde é uma condição para uma existência digna. Assim, pode-se dizer que a proteção à saúde (como condição de uma existência digna de qualquer cidadão) torna-se um dos mais relevantes pilares dos direitos fundamentas, e a Constituição Federal de 1988 não só estabeleceu isso claramente como descreveu o modo pelo qual o Estado deve assegurar a sua garantia.

Conforme definido por legislação, no Brasil a saúde é direito de todos e dever do Estado, competindo ao Sistema Único de Saúde - SUS a materialização deste direito. Ressalta-se que este direito é extensivo a todos os cidadãos brasileiros e estrangeiros regulares no país.

O SUS é orientado por diversos princípios, no entanto, a participação social é percebida como o mais democrático destes, pois possibilita à sociedade o exercício pleno da construção e manutenção do Sistema uma vez que a sociedade participa na elaboração e fiscalização das políticas que orientam o SUS.

No que tange à cidadania convém destacar que esta está fundamentada na proposta de que todos os homens são iguais perante a lei sem discriminação de raça, credo ou cor. A todos, cabe o domínio sobre seu corpo e sua vida, o direito à educação, à saúde, à habitação, ao lazer. Ter cidadania é ter o direito de se expressar livremente, defender partidos políticos e sindicatos, impulsionar movimentos sociais, lutar por seus valores ${ }^{10}$. Em síntese, ser cidadão é ter direito de ter uma vida digna de ser homem.

Neste sentido e levando-se em consideração a amplitude do conceito de cidadania infere-se dois movimentos: ter cidadania (como sujeito beneficiário de um direito) e exercer cidadania (como partícipe de um modelo social preconizado pela participação ativa). Pode-se dizer que exercer a cidadania é fazer parte do governo, ser agente da existência de direitos assim como seguir as normas e propostas elaboradas e decididas coletivamente, direta ou indiretamente, ao votar, ao pressionar através dos movimentos sociais, conselhos e assembleias.

Pode-se perceber que o anseio da população por melhores condições de vida e principalmente de saúde no referente aos produtos das Conferências apurados por meio dos Relatórios Finais investigados ganhou robustez ao longo do tempo, pois não era apenas por um sistema e sim o acesso e qualidade dos serviços por ele ofertados.

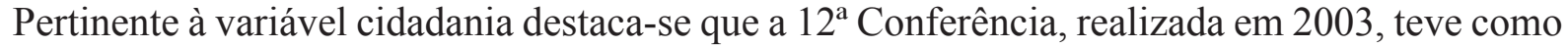
tema, Saúde: um direito de todos e um dever do Estado. A saúde que temos, o SUS que queremos. Tendo como eixos, a melhoria das condições de saúde e segurança dos trabalhadores, discussões sobre variáveis que interferem no alcance pleno da cidadania, diretrizes legais para garantir direitos, defender a redemocratização das relações entre sociedade e o Estado, garantir acesso aos documentos básicos, etc. 
Nas $13^{\mathrm{a}}$ e $14^{\mathrm{a}}$ Conferências temas foram Saúde e Qualidade de Vida: política de Estado e desenvolvimento e Estabelecer um sistema de saúde público e universal.

Verifica-se a importância de se ouvir a população para consolidar um sistema de saúde, sendo esta a mais qualificada para sinalizar quais sejam suas reais necessidades já que é esta quem faz uso do sistema.

A participação e o controle social em saúde se fazem importantes na definição de políticas, na regulação, financiamento e avaliação dos sistemas de serviços de saúde públicos e privados.

A participação social é um importante termômetro do desenvolvimento de uma sociedade com reflexos diretos sobre os níveis de saúde. Países onde há maior coesão social e maior participação política demonstram menores iniquidades em saúde ${ }^{11}$.

No Brasil, é a Lei 8.142, de 28 de dezembro de 1990, que regulamenta a participação da sociedade no SUS, determinando para cada esfera de governo duas instâncias de participação ${ }^{12}$ :

Conselhos de saúde: instância em caráter permanente e deliberativo trata-se de um órgão colegiado composto por seguimentos do governo, prestadores de serviço, profissionais de saúde e usuários. Os conselhos devem "atuar na formulação de estratégias e no controle da execução da política de saúde na instância correspondente, inclusive nos aspectos econômicos e financeiros, cujas decisões serão homologadas pelo chefe do poder legalmente constituído em cada esfera do governo".

Já as Conferências de saúde que se constituem fóruns de debate com a representação dos segmentos sociais, tem o objetivo de analisar a situação de saúde e propor diretrizes para a formulação das políticas de saúde.

Esses espaços decisórios são de grande importância para um maior fortalecimento da democracia participativa que "promove a subida da população a níveis cada vez mais elevados de participação decisória, acabando com a divisão de funções entre os que planejam e decidem lá em cima e os que executam e sofrem as consequências das decisões cá embaixo"13.

\section{CONCLUSÃO}

Percebe-se a contribuição histórica das CNS, sendo o SUS seu grande legado, assim como a extrema relevância nas discussões deflagradas em seus contextos imputados aos termos cidadania e democracia sendo o controle social/participação social o espaço mais profícuo a estas discussões.

E que têm cumprindo seu papel como fórum de debate com a representação dos seguimentos sociais, sendo capaz de analisar a situação de saúde e propor diretrizes para formulação de políticas públicas de saúde. 
Possibilitando à população brasileira a exercer sua cidadania com o aumento da participação nesses espaços democráticos. Visando buscar e construir novos rumos para o Sistema Único de Saúde, que foi construído por diversos atores, sobretudo pela população.

\section{REFERÊNCIAS BIBLIOGRÁFICAS}

${ }^{1}$ Michaelis: dicionário escolar língua portuguesa. São Paulo: Editora Melhoramentos, 2002.

${ }^{2}$ Brasil. Constituição (1988). Constituição da República Federativa do Brasil. Brasília: Senado Federal, 1988.

${ }^{3}$ Ferreira AG. Dicionário de Latim-Português. Porto - Portugal: Porto Editora, 1995.

${ }^{4}$ Brasil. Ministério da Saúde. O SUS de A a Z: garantindo saúde nos municípios. $3^{\text {a }}$ ed., $3^{\text {a }}$ reimpressão. Brasília: Editora do Ministério da Saúde, 2011.

${ }^{5}$ Brasil. Conselho Nacional de Secretários de Saúde. As Conferências Nacionais de Saúde: Evolução e perspectivas./ Conselho Nacional de Secretários de Saúde. - Brasília: CONASS, 2009. $100 \mathrm{p}$.

${ }^{6}$ Severino, AJ. Metodologia do Trabalho Científico. 23a ed. rev. e atualizada. São Paulo: Cortez, 2007.

${ }^{7}$ Poupart, J et. al. A pesquisa qualitativa: enfoques epistemológicos e metodológicos. $3^{\mathrm{a}}$ ed. Petrópolis - RJ: Editora Vozes, 2012.

${ }^{8}$ Escorel, S. História das políticas de Saúde no Brasil de 1964 a 1990: do golpe militar à reforma sanitária. Políticas e Sistema de Saúde no Brasil. Editora FIOCRUZ. Rio de Janeiro. 2012. 323363.

${ }^{9}$ Sarlet, Ingo Dignidade da Pessoa Humana e Direitos Fundamentais na Constituição Federal de 1988. 2. ed. Porto Alegre: Livraria do Advogado, 2002, p. 60

${ }^{10}$ ONU. Carta de Direitos da Organização das Nações Unidas. Disponível em: http://oas.org/ dil/port/1945\%20Carta\%20das\%20Na\%C3\%A7\%C3\%B5es\%20Unidas.pdf (Acesso em 10 jun 2015)

${ }^{11}$ Buss, PM; Pellegrinni, A. A Saúde e seus Determinantes Sociais. Physis: Rev. Saúde Coletiva, Rio de Janeiro, 17(1):77-93, 2007

${ }^{12}$ Esperidião, MA. Controle Social no SUS: Conselhos e Conferências de Saúde. Saúde coletiva: teoria e prática. MedBook. Rio de Janeiro. 2014. 245-259. 
${ }^{13}$ Bordenave, JED. O que é participação. 3. Ed. São Paulo: Brasiliense, 1985.

${ }^{14}$ Brasil. 8 a Conferência Nacional de Saúde - relatório final. Brasília: Ministério da Saúde, 1986.

${ }^{15}$ Brasil. IX Conferência Nacional de Saúde - relatório final. Brasília: Ministério da Saúde, 1992a.

${ }^{16}$ Brasil, Relatório final da $10^{\text {a }}$ Conferência Nacional de Saúde: Brasília: Ministério da Saúde, 1992b.

${ }^{17}$ Brasil. Relatório Final da $11^{\text {a }}$ Conferência Nacional de Saúde. O Brasil falando como quer ser tratado: efetivando o SUS: acesso, qualidade e humanização na atenção á saúde com controle social. Brasília. Editora do Ministério da Saúde, 2001.

${ }^{18}$ Brasil.12 $2^{\text {a }}$ Conferência Nacional de Saúde: Conferência Sergio Arouca: Brasília, 7 a 11 de dezembro de 2003: relatório final. Brasília: Ministério da Saúde, Conselho Nacional de Saúde, 2004.

${ }^{19}$ Brasil. Relatório Final da $13^{\text {a }}$ Conferência Nacional de Saúde: Saúde e Qualidade de vida: políticas de estado e desenvolvimento. Brasília: Editora do Ministério da Saúde, 2008.

${ }^{20}$ Brasil. Relatório Final $14^{\text {a }}$ Conferência Nacional de Saúde: Todos usam o SUS: SUS na seguridade social: Política pública, patrimônio do povo brasileiro. Brasília. Editora do Ministério da Saúde, 2012.

Artigo apresentado em 05-01-14 Artigo aprovado em 21-08-15 Artigo publicado no sistema em 22-12-15 